\title{
ROLE OF PLATELET TRANSFUSIONS IN DENGUE HEMORRHAGIC FEVER- 6 MONTHS REPORT
}

Dr. V. Geeta, Dr. Bheeshma, Dr. I. Srilakshmi, Dr.Ramya, Dr. Yashoda, Dr. Jijiya Bai.

1. Assistant Professor, Department of Pathology, Gandhi Medical College, Secunderabad.

2. Assistant Professor, Department of Pathology, Gandhi Medical College, Secunderabad.

3. Assistant Professor, Department of Pathology, Gandhi Medical College, Secunderabad.

4. Post Graduate, Department of Pathology, Gandhi Medical College, Secunderabad.

5. Medical Officer-Blood bank, Department of Pathology, Gandhi Medical College, Secunderabad.

6. Professor \& Head, Evaluator, Department of Pathology, Gandhi Medical College, Secunderabad.

\section{CORRESPONDING AUTHOR:}

Dr. V. Geetha, Assistant Professor of Pathology, Gandhi Medical College,

Secunderabad, Andhra Pradhesh, Email id- geethavoolapalli@gmail.com, Ph- 009109849450199.

\section{ABSTRACT:}

BACKGROUND: Allogenic platelet transfusion plays a major role in the management of thrombocytopenia. The study includes details of platelet transfusion over a period of 6 months from January-2011 to June-2011 at blood bank of Gandhi Hospital. Total number of patients who received were 487 and proportionate use of total units of RDP (Random Donor Platelets) issued from blood bank were as follows; dengue hemorrhagic fever (38\%) and remaining for acute leukemia (12\%), Aplastic anemia (10\%), sepsis (10\%), DIC (Disseminated Intravascular Coagulation) (10\%), cardiac surgery (10\%). In dengue hemorrhagic fever, correlation of platelet count with platelet transfusion and platelet increment have been evaluated.

KEYWORDS: Thrombocytopenia, RDP, DIC, Aplastic anemia.

AIM: To evaluate the role of platelet transfusion in dengue hemorrhagic fever.

\section{INTRODUCTION:}

Dengue infection is usually a benign syndrome caused by an arthropod born virus. Dengue fever and dengue hemorrhagic fever have emerged as a global public health problem in recent decades. The South East Asian Countries such as India, Indonesia and Thailand are at the highest risk of dengue accounting for nearly half of the global risk.

Dengue hemorrhagic fever (DHF) and dengue shock syndrome (DSS) are life threatening clinical manifestations ${ }^{1}$. The mechanisms of hemorrhagic manifestations of DHF/DSS are not well understood. The suggested factors contributing to bleeding include thrombocytopenia, coagulopathy and vasculopathy and Suggested mechanisms for thrombocytopenia include:

1) Maturational arrest of megakaryocyte production in the bone marrow

2) Platelet destruction by the virus it self

3) DIC 
The world health organization manual and text books of pediatrics and infectious diseases recommend infusion of fresh whole blood, fresh frozen plasma and/or platelet concentrates ${ }^{2}$. Theoretically the risk of spontaneous bleeding becomes significant at a platelet count of $<20 \mathrm{X}$ $10^{7} / \mathrm{ml}$.

\section{MATERIALS AND METHODS:}

A retrospective study was conducted in the blood bank of Gandhi Hospital for a period of 6 months from $1^{\text {st }}$ Jan to $31^{\text {st }}$ June 2011. Total no. of patients received platelet transfusion is 487 and total units of RDPs given are 1116. Patients clinical data, platelet count and platelet transfusion given to them were analyzed.

\section{RESULTS:}

Total no. of patients received platelet transfusion is 487 and total units of RDPs given are 1116 (Table.1), with males numbering 223 and females 264.

\begin{tabular}{|l|l|l|l|l|l|l|l|}
\hline Age Group & January & February & March & April & May & June & Total \\
\hline $0-10$ & 16 & 17 & 10 & 21 & 27 & 38 & 129 \\
\hline $11-20$ & 10 & 25 & 30 & 17 & 07 & 22 & 111 \\
\hline $21-30$ & 16 & 7 & 28 & 15 & 19 & 25 & 110 \\
\hline $31-40$ & 4 & 11 & 6 & 18 & 07 & 13 & 59 \\
\hline$>41$ & 12 & 10 & 9 & 9 & 13 & 15 & 68 \\
\hline Grand total & \multicolumn{7}{|l|}{} \\
\hline
\end{tabular}

Blood group wise distribution of platelet transfusion is as follows

$\begin{array}{ll}\text { B+ve: } & 180 \\ \text { O+ve: } & 178 \\ \text { A+ve: } & 161 \\ \text { AB+ve: } & 37 \\ \text { O-ve: } & 8 \\ \text { B-ve: } & 14\end{array}$

Distribution of platelet transfusion by diseases wise are (Fig.1)

\begin{tabular}{ll} 
Dengue confirmed patients & $-38 \%(186)$ \\
Acute leukemias (ALL + AML) & $-12 \%(58)$ \\
A plastic anemia & $-10 \%(49)$ \\
Sepsis & $-10 \%(49)$ \\
DIC & $-10 \%(49)$ \\
Cardiac patients & $-10 \%(49)$ \\
Others & $-10 \%(49)$ \\
\hline & 489 \\
\hline
\end{tabular}


Majority of Dengue patients belonged to B+ve and 0+ve Blood groups, most common age group is between 11 to 20 years (46\%) and females outnumbered males at 101 Vs 85.

During the study period 186 patients had positive serology (IgM or IgG) to dengue fever by ELISA method. Fever was the most common clinical presentation associated with headache, myalgia, vomiting, and diarrhea. Platelet count less than 10,000 / cumm noted in 20 patients $(10.7 \%)$.

\begin{tabular}{|c|c|c|c|}
\hline$<10,000$ & - 20 patients & $10.7 \%$ & High \\
\hline $11-20,000$ & - 36 patients & $19.35 \%$ & 115 \\
\hline $21-40,000$ & - 50 patients & 26. & Risk \\
\hline 1-1 lakh & - 80 patients & $43 \%$ & Risk \\
\hline
\end{tabular}

Most of the patients received platelet transfusion recovered completely and were discharged with 2-5 transfusions. The platelet count had picked up considerably. Guidelines for platelet transfusions in dengue hemorrhagic fever as follows:

\section{INDICATIONS:}

Prophylactic transfusions (in a non bleeding patient) with Platelet count $<20 \mathrm{X} 10^{9} / \mathrm{L}$ Therapeutic transfusions (in a bleeding patient)

1) Significant active clinical bleeding with platelet count $<50 \times 10^{9} / \mathrm{L}$.

2) DIC

\section{DISCUSSION:}

Dengue viruses belonging to the genus flavi virus of family flaviviridae has antigentically four distinct serotype DEN-1, DEN-2, DEN-3 and DEN-4. The virus is transmitted to the human being by the bite of infected Aedes Egypti Mosquito and few other members of Aedes species. Dengue virus causes a broad spectrum of illness ranging from mild undifferentiated fever to classical dengue fever, DHF, DSS.

Our study showed majority of dengue cases were children and adolescents in the age group of 10-20. Chaunsumrit et al also noted high percentage of dengue cases in age group of 1014 years $^{3}$. In contrast Ayyub et al and Lye et al noted adult preponderance in age group of 20-40 $\operatorname{yrs}^{4,5}$.

Thrombocytopenia is a common problem in dengue. In our study thrombocytopenia was found in all most all the confirmed cases of dengue which was equal when compared with findings of Makroo et al and Chairulfatah et al (84.88\% and 83\% respectively) ${ }^{6,7}$.

In our study bleeding occurred significantly more often in patients with thrombocytopenia most often in patients with platelet count less than 20,000 / cumm which is similar to Shivbalan et al. but chairulfatah et al found significant bleeding with platelet count less than 15,000 / cumm ${ }^{8,7}$. In our study high risk patient: platelet count < 20,000-30\%. Moderate risk: $27 \%(21,000-40,000)$ and Low risk: 43\% (40,000-1 lakh)

According to Makroo et al all Hospitalized patients with dengue with high risk should be given platelet transfusion ${ }^{6}$. 
Moderate risk patient can be given platelet transfusion if associated hemorrhagic manifestations are present. Low risk patients can be managed with IV fluids and supportive therapy. But in our study prophylactic transfusion of platelet given to $43 \%$ of low risk patients. Most of the patients (99\%) who received platelet transfusion recovered completely were monitored for increment of platelet count after 2-3 transfusion at the time of discharge the platelet count was above 1 lakh / cumm. Besides platelet transfusion FFP and PRP also transfused.

Death occurred in 3\% of patients due to complications like septicemia and severe bleeding with multi organ failure belonged to age group of 31-40.

\section{CONCLUSION:}

All Hospitalized dengue patients can be categorized into high, moderate and low risk patients based on platelet count at the time of Hospitalization. High risk patient should be given priority and platelet transfusion accordingly. In our study the outcome is good with $97 \%$ recovery of dengue patients with platelet transfusion and supportive therapy this clearly emphasizes the role of platelet transfusion in the management of dengue patients.

\section{Figure 1: Proportionate recipients of platelet transfusion}

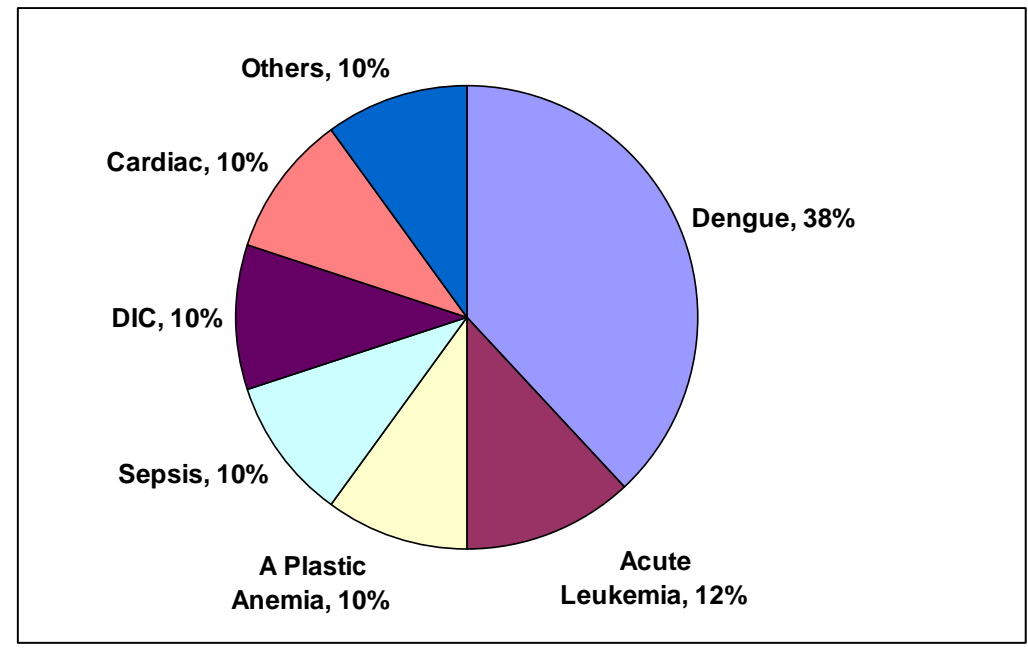

\section{REFERENCES:}

1. Directorate of health services, Management of Dengue Fever/DHF/DSS. Guidelines for indoor patients, 2005:4

2. World Health Organization (2009) Dengue: guidelines for diagnosis, treatment, prevention and control. World Health Organization, Geneva, pp 40-41.

3. Chuansumrit A, Phimolthares V, Tardtong P et al (2000) transfusion requirements in patients with dengue hemorrhagic fever. Southeast Asian J Trop Med Public Health 31:1014

4. Ayyub M, Khazindar AM, Lubbad EH et al (2006) Characteristics of dengue in a large public hospital, Jeddah, Saudi Arabia. J Ayub Medical coll Abbottabad 18:9-13 
5. Lye DC, Lee VJ, Sun Y, Leo YS (2009) Lack of efficacy of prophylactic platelet transfusion for severe thrombocytopenia in adults with acute uncomplicated dengue infection . Clin Infecct Dis 48:1262-1265

6. Makroo RN Raina V, Kumar P, Kanth RK (2007) Role of platelet transfusion in the management of dengue pts in a tertiary care hospital. Asian J Trans Sci 1:4-7

7. Chairulfatah A, Setibudi D, Agoes R, Colebunder R (2003) Thrombocytopenia and platelet transfusion in dengue. Haemorrhagic fever and dengue shock syndrome.WHO Dengue Bull 27:141- 143

8. Shivabalan S, Anandanathan K, Balasubramaniyan S, Dutta N, Amalraj E; predictors of spontaneous dengue, Indian J Ped. 2004; 71:33-6 (Pubmed) 